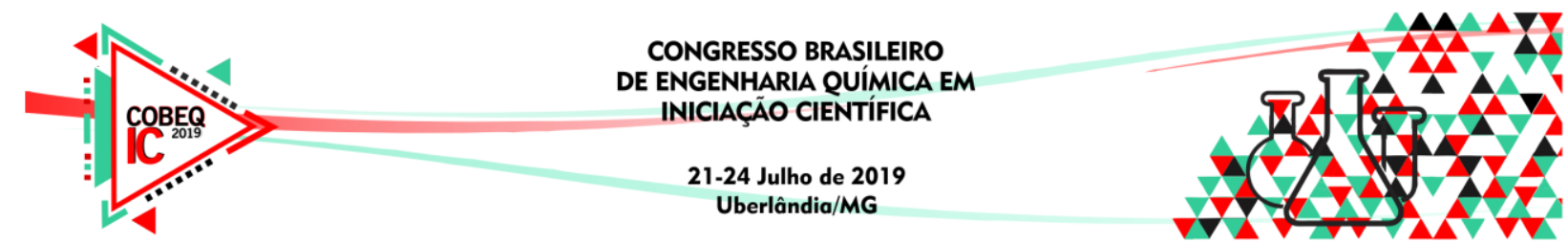

\title{
ESTUDO DA VIABILIDADE DA SECAGEM DE CAFÉ GOURMET VIA MICRO-ONDAS
}

\author{
ALVARENGA T. F. e PETRI I. J. \\ Universidade Federal de Lavras, Departamento de Engenharia \\ E-mail para contato: talvarenga@estudante.ufla.br
}

\begin{abstract}
RESUMO - Por ser um produto refinado, os cafés especiais visam exigências nas operações de secagem. Buscando alcançar meios alternativos para atender essa demanda, este trabalho objetivou o estudo de maneira experimental do processo de secagem do grão de café gourmet via aquecimento micro-ondas, trazendo a otimização de tempo com a tecnologia de secagem híbrida, que é provida de processos convectivos e de micro-ondas. Isto é possível, pois, a energia provinda das micro-ondas acelera a secagem quando comparada com a secagem feita somente pelas convencionais. Além disso, um maior controle dos parâmetros do processo pôde ser analisado com maior convicção de que o produto apresentaria uma maior uniformidade nas estruturas dos grãos. Para tanto, foram avaliados, os parâmetros influentes no aquecimento como: potência do forno de micro-ondas, energia específica, teor de umidade dos grãos de café gourmet, entre outros, e assim, feitas curvas cinéticas de aquecimento para avaliar a viabilização do processo.
\end{abstract}

\section{INTRODUÇÃO}

Hoje o Brasil é um dos maiores exportadores de café do mundo, tendo alcançado 1008 mil toneladas de café no ano de 2018, e prevê um aumento de 3,5\% para o ano de 2019, de acordo com a ABIC (Associação Brasileira da Indústria de Café). Visando a sua importância no âmbito mundial é de suma necessidade conhecer bem o produto e garantir a sua qualidade. O teor de água dos grãos de café é um dos fatores que mais interfere no seu preparo até chegar ao estágio de consumo. Por isso, a secagem de grãos de café é amplamente utilizada no mundo agrícola, principalmente para o controle, a manutenção da sua qualidade e o seu posterior armazenamento.

Sabe-se que os grãos de café, assim como ademais produtos agrícolas, em sua maioria, são altamente higroscópicos, ou seja, tem grande afinidade com a água, absorvendo-a do meio em que se encontram. A secagem então, se torna necessária devido a essa propriedade dos grãos, visando o não comprometimento do armazenamento e da qualidade do produto final. Outra vantagem é a redução moderada do peso, o que facilita o transporte do mesmo. $\mathrm{O}$ período convencional de secagem ocorre de 1 até 12 dias consecutivos, (CUNHA, et al. 2013) dependendo das condições dos grãos e dos meios operacionais. Nesse longo período, o material pode se danificar por diversos meios. Uma das fontes alternativas que está se propagando nos países industrializados, são as técnicas de aquecimento por micro-ondas. 


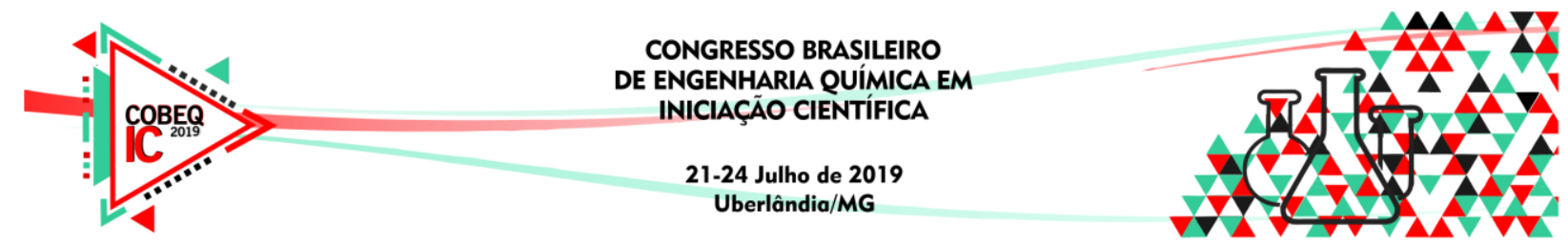

"Um campo de micro-ondas causa aquecimento volumétrico do sólido úmido, levando a um gradiente de pressão de vapor de água entre a superfície e a parte interna do material e acelera a transferência de umidade" (ROKNUL et al., 2014 ; SCHULZE et al., 2014). Ou seja, as ondas agem de forma instantânea nos grãos de café, em que a conversão de energia de calor ocorre em um menor período de tempo, o que acelera a produtividade. Além desta, há outras vantagens ao utilizar as micro-ondas para tal como, a economia de energia e a preservação dos compostos presentes nos grãos de café que são sensíveis à temperatura. $\mathrm{O}$ café gourmet assim como os ademais tipos de café necessita de toda uma preparação, para então ser consumido, por isso os cuidados devem ser ainda maiores.

"O café gourmet é um produto refinado, de qualidade superior à do café tradicional, e, por consequência, também de preço bem superior ao dele. O consumidor que opta por pagar bem mais caro por um produto, por ele ser de qualidade superior ao produto padrão, quer ter, em troca, diversidade de prazeres e sentimentos de que ele acredita que pode desfrutar no ato do consumo.", como diz Pessôa \& Souza (2010, p. 85). Para isso, a secagem dos grãos de café gourmet deve ocorrer no máximo de $40^{\circ} \mathrm{C}$, e sua umidade deve ser preservada dentro do intervalo de 11 a $13 \%$ b.u. (base úmida). Esse intervalo de umidade garante que o café seja armazenado por mais tempo sem que ocorra alteração no seu sabor e na sua aparência.

A energia de micro-ondas combinada com outros métodos de secagem pode melhorar a eficiência da secagem, bem como a qualidade dos produtos alimentícios. Esta se mostra muito melhor do que a alcançada pela aplicação de cada método sozinho. Assim, optou-se pelo uso da secagem híbrida. Esta utiliza do acoplamento da secagem micro-ondas com a convencional. Para realização deste trabalho, nos grãos de café do tipo gourmet, será aplicado tal método, a fim de validar a eficiência do processo e da qualidade final do produto. (BOTHA et al., 2019).

\section{METODOLOGIA}

Inicialmente foi construída a unidade experimental com sistema de aquisição de dados, assim como mostrado na Figura 1. Os experimentos de secagem foram realizados e executados nos Laboratórios de Operações de Separação Térmica da Engenharia Química da Universidade Federal de Lavras (UFLA). Para tal procedimento, foi necessária a colheita das amostras de café gourmet, a mesma realizada na Agência de Inovação de Café (Innova Café) da UFLA, e em seguida, realizou-se um tratamento pós-colheita para obtenção de um café gourmet despolpado, visto na Figura 2 e 3, seguido da etapa de caracterização, para obter as propriedades físico-químicas.

Figura 1 - Unidade experimental de secagem micro-ondas de café gourmet.

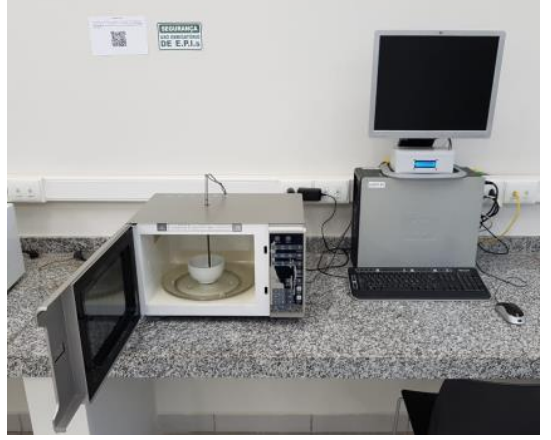




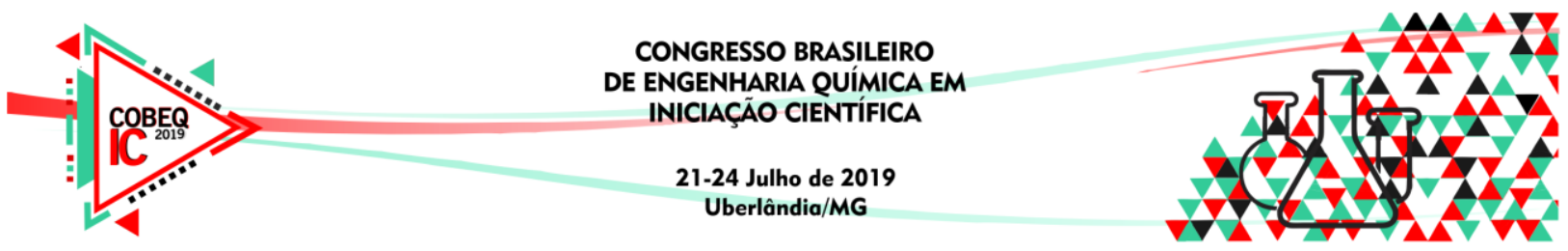

Figura 2 - Tratamento póscolheita a fim de obter as amostras de grãos de café.

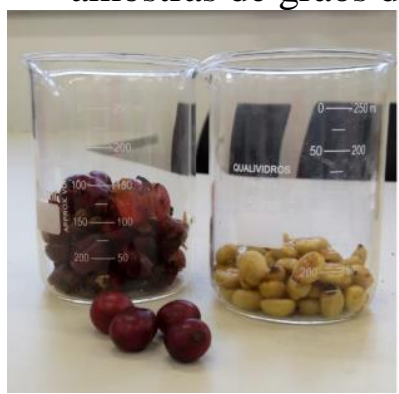

Figura 3 - Grãos de café antes e depois da desmucilagem.
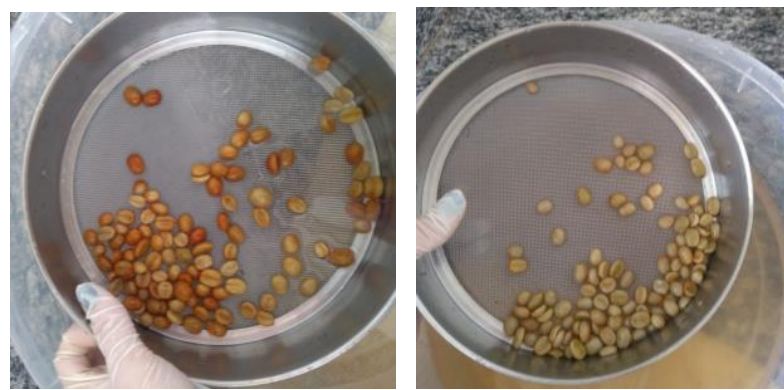

Antes de iniciar os procedimentos fez-se a calibração da potência de saída do forno de micro-ondas para suas respectivas frações de potências mostradas no painel do fabricante: 20, 40, 60, 80 e 100\%. Para tal, utilizou-se a norma IEC 60705 (International Electrotechnical Commission) e Portaria $\mathrm{n}^{\mathbf{0}}$ 174/2012 do INMETRO (Instituto Nacional de Metrologia, Qualidade e Tecnologia). Através de um termopar tipo k acoplado à placa de aquisição (DAQ 6009), foi possível obter as temperaturas iniciais e finais para cada teste realizado.

Para tomar ciência da quantidade de amostra necessária para cada analise, foi calculada a densidade bulk e a fração mássica da casca e a fração mássica dos grãos.

$\mathrm{O}$ teor de umidade do café também foi medido com o auxílio da balança semi-analítica e de uma estufa com circulação de ar à uma temperatura de $105^{\circ} \mathrm{C}$ por $24 \mathrm{~h}$ em triplicata. $\mathrm{O}$ café seco em estufa pode ser observado na Figura 4.

Figura 4 - Amostras de café após 24 horas na estufa.

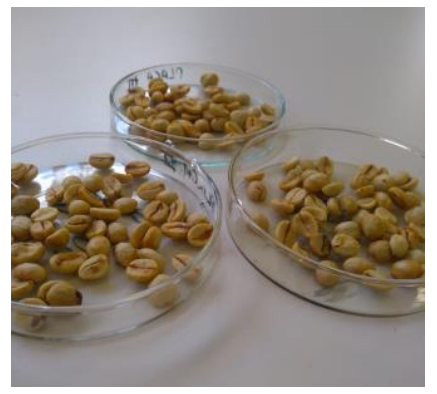

Para as análises de cinética de aquecimento, amostras de $150 \mathrm{~g}$ foram postas em um cadinho de cerâmica e assim alocado no interior da cavidade do forno de micro-ondas. Juntamente a amostra, foi inserido o termopar que possibilitou o monitoramento da temperatura durante o período de aquecimento micro-ondas, que como dito, é de extrema importância para a classificação do café gourmet. Para tal, as ondas eletromagnéticas no interior do forno micro-ondas agem de forma instantânea nos grãos de café, aquecendo-o de dentro para fora. Assim, a secagem ocorre em um menor período de tempo, o que acelera o tempo de secagem. Quando a amostra obteve uma temperatura próxima aos $150^{\circ} \mathrm{C}$, findou-se o experimento para evitar entrar na etapa de torrefação do café. Repetiu-se o procedimento para diferentes potencias do forno micro-ondas. 


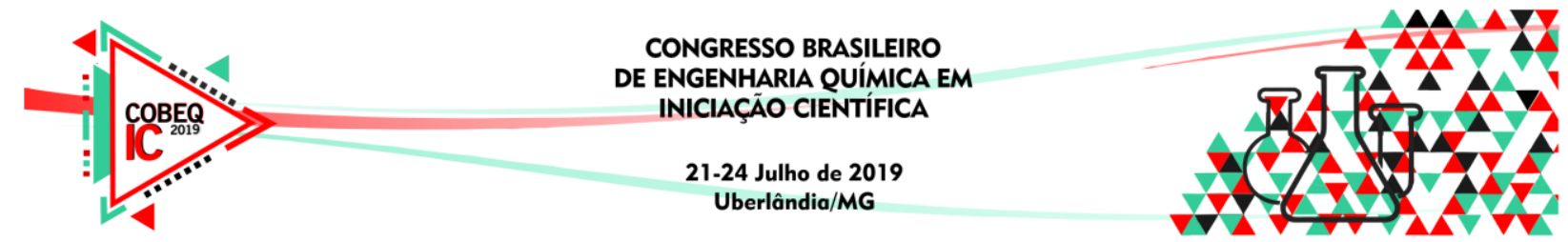

\section{RESULTADOS E DISCUSSÕES}

Através dos testes preliminares de caracterização do café gourmet utilizado neste trabalho, pôde-se gerar a Tabela 1 que se refere às propriedades físicas do mesmo. Através dos ensaios de secagem pôde-se gerar a Tabela 2, que se refere ao teor de umidade em base úmida dos grãos para as diferentes potências utilizadas.

Tabela 1 - Propriedades físicas do café gourmet utilizadas neste trabalho.

\begin{tabular}{|c|c|c|}
\hline Propriedade & Valor médio & Desvio padrão \\
\hline \hline $\begin{array}{c}\text { Densidade bulk das sementes } \\
{[\mathbf{k g} / \mathbf{m} 3]}\end{array}$ & 670,0 & 0,00001 \\
\hline Fração mássica de casca [\%] & 40,3 & 0,004 \\
\hline Fração mássica de semente [\%] & 59,7 & 0,005 \\
\hline Teor de umidade (base seca) [\%] & 135 & 0,007 \\
\hline Teor de umidade (base úmida) [\%] & 57,0 & 0,002 \\
\hline
\end{tabular}

Tabela 2 - Parâmetros de secagem para diferentes potências.

\begin{tabular}{|c|c|c|}
\hline Potência de secagem & $\begin{array}{c}\text { Tempo de secagem } \\
\text { (min) }\end{array}$ & $\begin{array}{c}\text { Teor de umidade (base úmida) } \\
{[\%]}\end{array}$ \\
\hline \hline $\mathbf{1 0 0}$ (watts) ou 10\% & 73,5 & zero \\
\hline $\mathbf{3 0 0}$ (watts) ou $\mathbf{3 0 \%}$ & 33,5 & zero \\
\hline $\mathbf{5 0 0}$ (watts) ou $\mathbf{5 0 \%}$ & 13,5 & zero \\
\hline $\mathbf{1 0 0 0}$ (watts) ou $\mathbf{1 0 0 \%}$ & 7,0 & 54,88 \\
\hline
\end{tabular}

Através da Tabela 1 observa-se que a fração de grãos de café é maior que a fração da casca, o que favorece tanto na pesquisa quanto na produção final para os produtores. Outro beneficio é a redução de resíduos gerados pela mesma. Outro ponto a se observar são os equivalentes aos valores de umidade, onde mostra que há uma grande quantidade de água no café, o que justifica a necessidade da secagem para diminuir a atividade de água do grão possibilitando a longevidade do armazenamento do mesmo.

Através da Tabela 2 percebe-se que o teor de umidade para as potências de 300, 500 e 1000 watts chegaram $0 \%$, porém, para tais potências, houve degradação de matéria devida à alta temperatura alcançada num pequeno intervalo de tempo. Para a potência de 300 watts, houve uma perda $21,303 \mathrm{~g}$ de café carbonizado, o que foi comprovado visualmente. Para a potência de 500 watts, foram perdidos $1,839 \mathrm{~g}$ de café. Já para a potência de 1000 watts, foram perdidos $9,35 \mathrm{~g}$ de café. Para a potência de 100 watts o teor de umidade chegou 


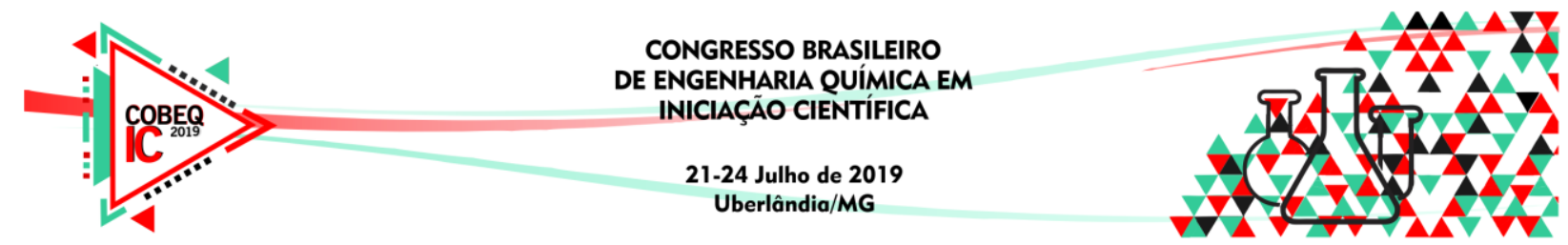

próximo ao do grão de café que são de $57 \%$ de umidade. Logo, como não houve perda de café por carbonização, consta que essa é a melhor potência a se trabalhar, e para correção da umidade ainda restante, basta aumentar o tempo de secagem.

Para tais análises, construíram-se curvas de cinética de aquecimento geradas nos testes com café gourmet para as potências citadas na Tabela 2, mostradas na Figura 5.

Figura 5 - Curvas de cinética de aquecimentos do café em diversas potências analisadas.

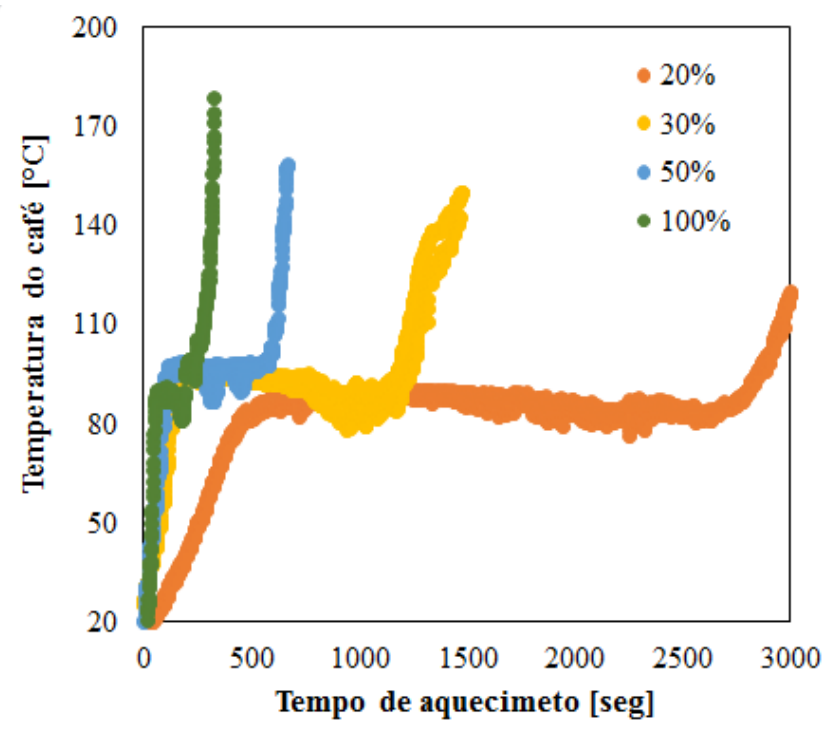

Analisando os resultados da Figura 5, verifica-se que todas as curvas de potências do experimento obtiveram 3 fases para o perfil de aquecimento. A primeira ocorre quando o café, devido sua característica higroscópica, absorve as micro-ondas e converte a energia em calor sensível, o que eleva a temperatura de maneira linear e inclinação dependente da potência utilizada. A segunda fase é aquela em que a temperatura se manteve constante, em torno de $100^{\circ} \mathrm{C}$, onde a energia absorvida é convertida em calor latente, vaporizando a água que está incorporada ao café. $\mathrm{Na}$ terceira etapa, a umidade está bem baixa, e parte da energia das micro-ondas é utilizada para vaporizar o restante da água que permanece no grão e a outra parte é utilizada para aumentar a temperatura do leito. Assim o café inicia seu processo de torrefação, onde à $150^{\circ} \mathrm{C}$ já se pode observar tal acontecimento.

A inclinação da reta presente na primeira fase varia de acordo com a potência aplicada, onde o ângulo reduz diretamente proporcional a ela. Já na segunda fase, o perfil de temperatura se torna constante devido à secagem do grão, e sua extensão pelo eixo $\mathrm{x}$ se dá pela potência utilizada. Para altas potências, o tempo de permanência nessa fase foi menor do que para as baixas potências.

\section{CONCLUSÃO}

Neste trabalho pôde ser visto que a secagem do café a altas temperaturas gera um café de qualidade inferior àquele denominado gourmet. Isso se deve ao fato de os grãos de café sofrerem um alto aquecimento em curto período de tempo, o que faz com ocorra uma perda 


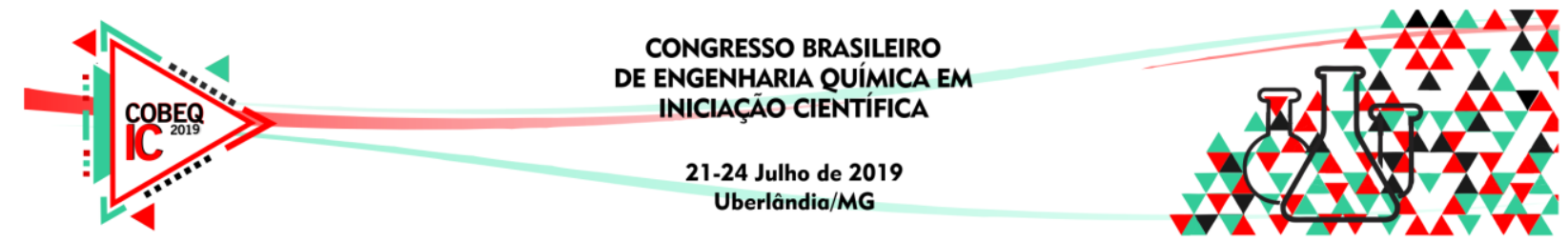

significativa de suas características físico-químicas. Porém o contrário também é observado. Quando utilizada baixas potências, ocorre uma secagem uniforme nos grãos de café, mantendo suas características inalteradas. Além disso, quando comparada a secagens convencionais, as micro-ondas realizam o procedimento de maneira otimizada, comprovando sua eficiência para tal. Quando analisadas as curvas de cinéticas químicas, vê-se claramente que os grãos passam pelos três estágios de secagem, primeiro a absorção das micro-ondas transformando a umidade em calor sensível; a segunda onde a temperatura se mantem constante e parte da umidade se transforma em calor latente; e a terceira onde o restante da água é vaporizado iniciando a torra do café. Outro fato a se concluir, é que para melhorar a secagem evitando a perda e a degradação do café gourmet, vimos que quando o forno de micro-ondas se encontra em $10 \%$ de sua potência, ou seja, a 100 watts, sua taxa de umidade se reduziu próximo ao valor esperado de $57 \%$ na base umidade em que os grãos de café contêm. Então, para tal melhora, basta aumentar o tempo de secagem e assim atingindo os parâmetros requeridos.

Por mais, para aumentar a eficiência do experimento, pode-se unir o uso das microondas a outros métodos convectivos, o que é denominado como secadores híbridos. Assim, seria benéfico ao aumento da produção e a redução do tempo necessário para a secagem.

\section{REFERÊNCIAS}

PESSÔA, Diego José, and Maria José Scassiotti de Souza. "A marca como instrumento agregante de valor para o produto brasileiro no exterior: o caso do café gourmet." Revista Eletrônica de Negócios Internacionais 5.1 (2010): 84-111.

CORRÊA, Paulo Cesar, et al. "Modelagem matemática e determinação das propriedades termodinâmicas do café (Coffea arabica L.) durante o processo de secagem." (2010).

PETRI, I. J.; Descontaminação de cascalhos de perfuração utilizando um secador micro-ondas semi-industrial em regime contínuo, Tese de Doutorado, Universidade Federal de Uberlândia, Uberlândia - MG, 2017.

CUNHA, M. L.; CANTO M. W.; MARSAIOLI, A. J.; Secagem de café cereja descascado por ar quente e micro-ondas, Ciênc. Tecnol. Aliment., Campinas.

CASTRO, L. E.; Efeito do despolpamento, em secador de leito fixo sob alta temperatura, no consumo de energia e na qualidade do café (Coffea arabica L.). 1991. 61 p.- Viçosa.

JUNQUEIRA, J. R. J.; CORRÊA, GOMES, J. L.; ERNESTO, D. B. Microwave, convective, and intermittent microwave-convective drying of pulsed vacuum osmo dehydrated pumpkin slices. Journal of food processing and preservation, v. 41, p. e 13250, 2017.

SCHULZ, S., et al. "The role of microorganisms at different stages of ecosystem development for soil formation." Biogeosciences 10.6 (2013): 3983-3996.

COETZEE, MElINDE, et al., eds. Practising Learning and Development in South African Organisations. Juta (Pty) Limited, 2019. 

INICIAÇÃO CIENTÍFICA

21-24 Julho de 2019

Uberlândia/MG

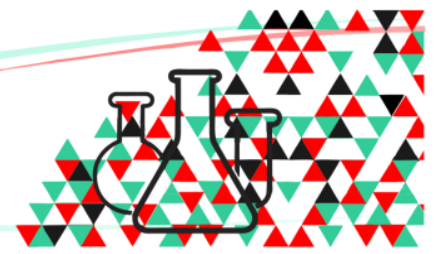

